\title{
The Incorporation of Strontium in a Sodium Alginate Coating on Titanium Surfaces for Improved Biological Properties
}

\author{
Ning Yuan, ${ }^{1,2}$ Lili Jia, ${ }^{3}$ Zhen Geng, ${ }^{3}$ Renfeng Wang, ${ }^{2}$ Zhaoyang Li, ${ }^{3}$ Xianjin Yang, ${ }^{3}$ \\ Zhenduo Cui, ${ }^{3}$ Shengli Zhu, ${ }^{3}$ Yanqin Liang, ${ }^{3}$ and Yunde Liu ${ }^{2}$ \\ ${ }^{1}$ Department of Laboratory Medicine, Tianjin Chest Hospital, Tianjin 300051, China \\ ${ }^{2}$ School of Laboratory Medicine, Tianjin Medical University, Tianjin 300072, China \\ ${ }^{3}$ School of Materials Science \& Engineering, Tianjin Key Laboratory of Composite and Functional Materials, Tianjin University, \\ Tianjin 300350, China
}

Correspondence should be addressed to Zhaoyang Li; zyli@tju.edu.cn

Received 5 May 2017; Accepted 4 July 2017; Published 3 October 2017

Academic Editor: Adriana Bigi

Copyright (c) 2017 Ning Yuan et al. This is an open access article distributed under the Creative Commons Attribution License, which permits unrestricted use, distribution, and reproduction in any medium, provided the original work is properly cited.

\begin{abstract}
Orthopedic implant failure is mainly attributed to the poor bonding of the implant to bone tissue. An effective approach to minimize the implant failure would be modifying the surface of the implant. Strontium (Sr) can stimulate the proliferation and differentiation of osteoblasts and reduce the activity of osteoclasts. In this study, a titanium (Ti) surface was successively functionalized by covalently grafting dopamine, sodium alginate (SA), and $\mathrm{Sr}^{2+}$ via the electrostatic immobilization method. The as-prepared coatings on the Ti surface were characterized by using scanning electron microscopy (SEM), X-ray photoelectron spectroscopy (XPS), Fourier transform infrared spectroscopy (FT-IR), and contact angle. The results indicated that the Sr-incorporated coatings were successfully prepared and that Sr distributed uniformly on the surface. A long-lasting and sustained Sr release had been observed in $\mathrm{Sr}^{2+}$ release studies. The Ti/DOPA/SA/Sr exhibited little cytotoxicity and a robust effect of Sr incorporation on the adhesion and spreading of MG63 cells. The proliferation and alkaline phosphatase (ALP) activity of MG63 cells were enhanced by immobilizing $\mathrm{Sr}^{2+}$ on the SA-grafted Ti. The Sr-containing coatings, which displayed excellent biocompatibility and osteogenic activity, may provide a promising solution for promoting the tissue integration of implants.
\end{abstract}

\section{Introduction}

Titanium (Ti) and its alloys, which have excellent mechanical properties and chemical stability, are commonly used as orthopedic and dental implant materials [1-3]. A spontaneously formed oxide layer on a $\mathrm{Ti}$ surface can provide it with biocompatibility and bioactivity [4]. On attaining complete adhesion between the implant and host bone tissue, however, it is not efficient in terms of the risk of the implant loosening over time, resulting in ultimate implant failure [5]. Consequently, many efforts are being devoted to methods of modifying the surface of Ti to achieve the desired biological responses [6]. The titanium oxide layer with an incorporated bioactive ion, which promotes osteoblast differentiation and increases biomechanical anchorage, has become a very active research area [7-10].
Strontium (Sr), which has recently drawn a lot of attention, plays an important role in the enhancement of implant bone healing. Several researchers involved with in vivo and in vitro studies have reported the beneficial effects of $\mathrm{Sr}$ on bone metabolism [11-13]. In vivo, Sr presents in the region of bone mineralization. It can stimulate the proliferation and differentiation of osteoblasts and inhibit the activity of osteoclasts, consequently enhancing matrix deposition and ultimately new bone formation [14]. Strontium ranelate has been proven to favor bone healing by both increasing new bone formation and reducing bone resorption [15-18].

In recent studies, $\mathrm{Sr}$ has been experimentally incorporated into various bone implantation biomaterials [13, $16,17,19-23]$. Sr incorporations in calcium phosphate and hydroxyapatite coatings have been widely investigated. Li et al. [17] found that $\mathrm{Sr}^{2+}$-substituted hydroxyapatite coatings 


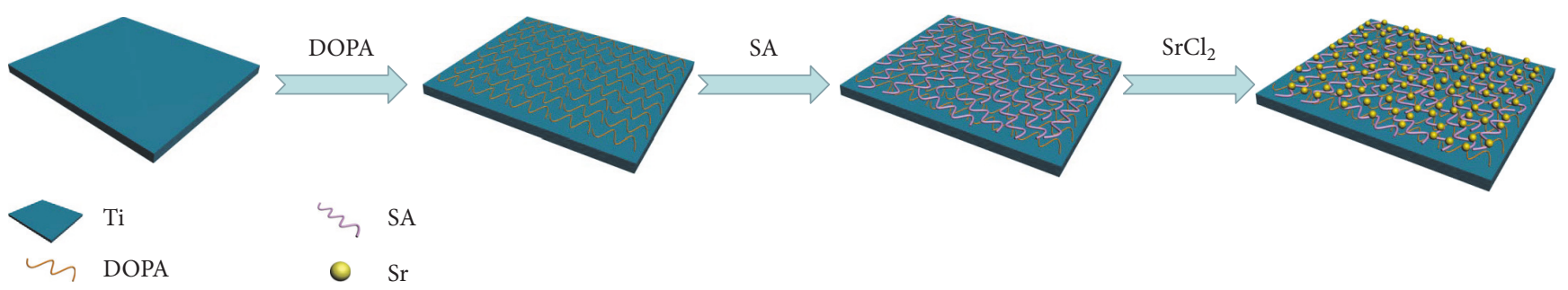

(a)
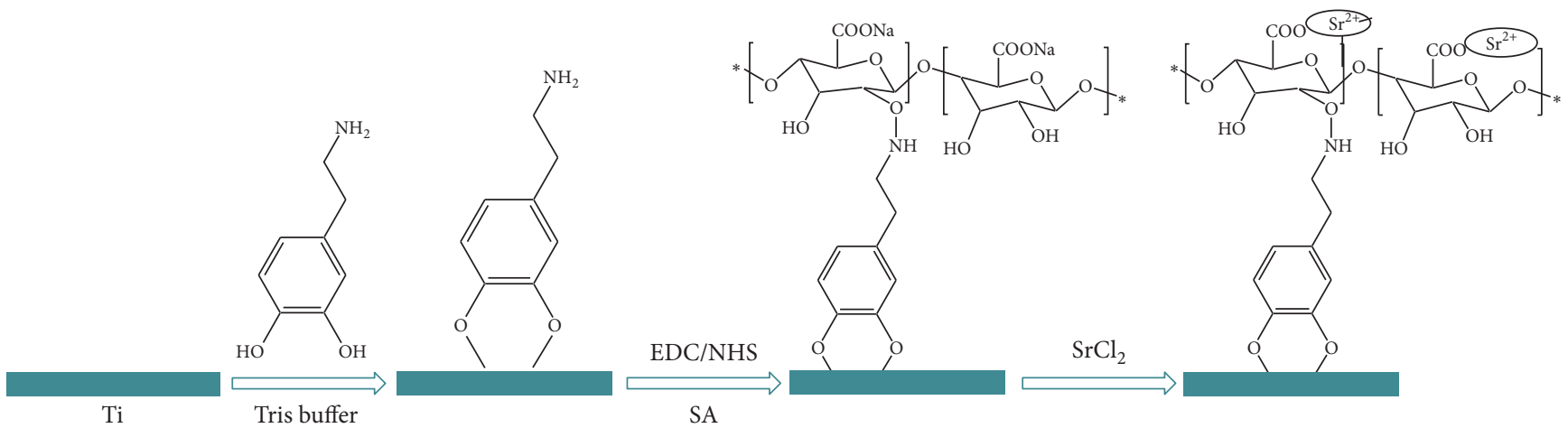

(b)

FIgURE 1: (a) Schematic illustration of the preparation process of Sr-incorporated alginate coating on titanium surface. (b) The molecular formula of Sr-incorporated alginate coating on titanium surface.

with $10 \mathrm{~mol} \% \mathrm{Ca}^{2+}$ replaced by $\mathrm{Sr}^{2+}$ could enhance implant osseointegration in ovariectomized rats. Capuccini et al. [16] showed that hydroxyapatite substituted by a suitable dosage of strontium could promote the attachment and proliferation of osteoblasts. Ni et al. [13] demonstrated that Sr-containing hydroxyapatite bone cement exhibited better bioactivity than hydroxyapatite bone cement in a revision hip replacement model using goats. Thus, Sr incorporation may be considered as an effective way to enhance the osteoconductivity of implants. It would also be expected that Sr-containing organic coatings on Ti might improve implant bone healing. Sodium alginate (SA), an organic polymer material with plenty of hydroxyl and carboxyl, has good chelation of Sr [24-26]. It could be an efficient delivery platform with controlled Sr releasing. Moreover, as an abundant natural polysaccharide, SA has excellent biocompatibility and stability [27]. Thus, the SA coating incorporated with $\mathrm{Sr}^{2+}$ on $\mathrm{Ti}$ is expected to have considerable potential in implant modification.

It is difficult to prepare the SA coating for $\mathrm{Ti}$ with a smooth surface. Inspired by the adhesive proteins secreted by mussels for attachment to wet surfaces, several researchers have found dopamine (DOPA, or 3,4-dihydroxy-phenylalanine) to be an appropriate main constituent to attach to the wet surface [28-30]. It could form strong covalent and noncovalent interactions with substrates. Moreover, the existence of catechol groups in DOPA makes it a potentially excellent anchor on all types of materials.

In this study, a SA coating-incorporated $\mathrm{Sr}^{2+}$ is fabricated via the strong interaction of DOPA on Ti. The experiment's schematic is shown in Figure 1. The composition and properties of the modified Ti surface are subsequently investigated and analyzed. Finally, cell morphology, cytotoxicity, proliferation, and ALP activity are assayed.

\section{Materials and Methods}

2.1. Materials. Commercial pure Ti (99.6\%) was purchased from Zhongtian Co., Ltd. (China). Dopamine (dopamine hydrochloride), sodium alginate $(\mathrm{Mw} \sim 25 \mathrm{kDa})$, hydrochloric acid, sodium hydroxide, acetone, ethyl alcohol, tris(hydroxymethyl)aminomethane, strontium chloride, 1-ethyl-(3-dimethylaminopropyl)carbodiimide (EDC), and N-Hydroxysuccinimide (NHS) were obtained from Sigma-Aldrich (USA).

2.2. Preparation and Pretreatment of Ti. The commercial pure Ti was cut into $10 \mathrm{~mm} \times 15 \mathrm{~mm}$ plates. These plates were polished using 800- and 1500-grid sandpaper and then were cleaned ultrasonically for 10 min successively in acetone, ethanol, and water. To wipe out the deposited carbide and prepare a tight porous structure, Ti plates were put into $40 \mathrm{wt} . \% \mathrm{HNO}_{3}$ for ultrasonic cleaning for $40 \mathrm{~min}$. Then the acid-treated plates were rinsed thoroughly with deionized water, placed in the $5 \mathrm{~mol} / \mathrm{L} \mathrm{NaOH}$ at $90^{\circ} \mathrm{C}$ for $5 \mathrm{~h}$, and subsequently cleaned ultrasonically in water for $30 \mathrm{~min}$.

2.3. Preparation of the Coatings on Ti. To prepare the DOPA coating on the Ti, DOPA was firstly anchored to the surface of the Ti after acid and alkali treatment. The Ti plates were immersed in a $1 \mathrm{~g} / \mathrm{L}$ aqueous solution of DOPA overnight in the dark, and then the plates were rinsed with ultrapure water to remove the unattached DOPA and dried under 
the dynamic nitrogen atmosphere. The resulting plates were denoted as Ti/DOPA.

To prepare the SA coating on the Ti, $0.5 \mathrm{~g} \mathrm{SA}$ was added to $50 \mathrm{ml} \mathrm{H} \mathrm{H}_{2} \mathrm{O}$. After the SA was dissolved adequately in the water, $0.3881 \mathrm{~g}(50 \mathrm{mmol} / \mathrm{L}) \mathrm{EDC}$ and $0.2875 \mathrm{~g}(50 \mathrm{mmol} / \mathrm{L})$ NHS were put into the SA solution. Then, the SA solution continued to be stirred overnight. The Ti/DOPA samples were placed into SA solution at $37^{\circ} \mathrm{C}$. After $12 \mathrm{~h}$, the plates were taken out and rinsed with ultrapure water to remove the unattached SA. The SA-treated plates were denoted as Ti/DOPA/SA.

The Ti/DOPA/SA samples were treated in a $20 \mathrm{~mL}$ aqueous solution of $\mathrm{SrCl}_{2}$ overnight at $37^{\circ} \mathrm{C}$ to prepare the $\mathrm{Sr}$ coating. The $\mathrm{SrCl}_{2}$ concentrations were $1 \mathrm{wt} . \%$ and $5 \mathrm{wt} . \%$, respectively. As noted in the following discussion, they were denoted as Ti/DOPA/SA/Sr1 and Ti/DOPA/SA/Sr5, respectively. After the overnight reaction, the surfaces were rinsed by pipetting $1 \mathrm{~mL}$ of ultrapure water over the surface to remove the excess $\mathrm{SrCl}_{2}$, and the rinse solutions were collected and stored for further analysis.

2.4. Surface Characterization. The functional groups of the surface coatings were analyzed by attenuated total reflection infrared (ATR-IR) spectroscopy. The ATR-IR spectra of the coatings were recorded on the spectrometer using a singlereflection horizontal ATR accessory (Bruker Vertex 70). Each spectrum was collected in the range of $4000-400 \mathrm{~cm}^{-1}$ by cumulating 32 scans at a resolution of $4 \mathrm{~cm}^{-1}$. The surface morphologies of the coatings were conducted by fieldemission scanning electron microscopy (S-4800, Hitachi, Japan). An accelerating voltage of $10 \mathrm{kV}$ was chosen for a scanning electron microscopy (SEM) analysis, and micrographs were captured using secondary electrons collected with an in-lens detector. To elucidate the status of the elements, the samples were characterized by XPS using a PHL1600ESCA instrument equipped with a monochromatic $\mathrm{Mg} \mathrm{Ka} X$-ray source $(E=1253.6 \mathrm{eV})$ operated at $250 \mathrm{~W}$. The analysis spot had a diameter of $200 \mu \mathrm{m}$, and the detection angle relative to the substrate surface was 45 . The dynamic contact angle analysis using double-distilled water was performed utilizing a JCD2000 drop shape analysis system (Powereach Co., Shanghai, China). The initial distilled water volume was $5 \mu \mathrm{L}$, and the measurement was performed at ambient temperature. For each group, the mean value of the contact angle was calculated from 5 individual measurements.

2.5. $\mathrm{Sr}^{2+}$ Release Characterization. $\mathrm{Sr}^{2+}$ release behaviors from Ti/DOPA/SA/Sr1 and Ti/DOPA/SA/Sr5 were investigated by immersion in $5 \mathrm{~mL}$ of phosphate-buffered saline (PBS) at $37^{\circ} \mathrm{C}$. Measurements were taken at $12 \mathrm{~h}, 1 \mathrm{~d}, 2 \mathrm{~d}$, $3 \mathrm{~d}, 5 \mathrm{~d}, 7 \mathrm{~d}, 9 \mathrm{~d}, 13 \mathrm{~d}, 17 \mathrm{~d}, 21 \mathrm{~d}$, and $28 \mathrm{~d}$. The amount of the released $\mathrm{Sr}^{2+}$ was measured using inductive coupled plasma optical emission spectroscopy (ICP-OES, Optima 3000 DV (PerkinElmer)). The $\mathrm{Sr}^{2+}$ concentration was calculated based on the previous measurements. Ultimately, the $\mathrm{Sr}^{2+}$ release curve was expressed in a plot with the accumulated $\mathrm{Sr}^{2+}$ versus time.

\subsection{Cell Experiments}

2.6.1. Cell Culture. Osteoblast-like cells (MG63) were cultured in a high-glucose DMEM medium supplemented with $10 \%$ fetal bovine serum (FBS) and $100 \mathrm{unit} / \mathrm{mL}$ penicillin. Cell cultures were maintained at $37^{\circ} \mathrm{C}$ under a humidified atmosphere of $5 \% \mathrm{CO}_{2}$ in air, and the growth medium changed every 2 to 3 days. The cells were passaged every 2 days.

2.6.2. Cell Morphology. The samples were placed into 12microwell plate and seeded with MG63 cells at a density of $2 \times 10^{4}$ cells/well. After the MG63 cells were diluted by the DMEM medium, a $50 \mu \mathrm{L}$ cell suspension solution $\left(2 \times 10^{4}\right.$ cells $/ 50 \mu \mathrm{L}$ ) was first carefully seeded on the samples, and then $1 \mathrm{~mL}$ medium was added to each sample well. After $6 \mathrm{~h}$ and $12 \mathrm{~h}$ of culturing, the medium was extracted, and $1 \mathrm{~mL}$ paraformaldehyde (4\%) was put into each sample well to fix cells on the samples for $30 \mathrm{~min}$. After this, $30 \%, 50 \%, 70 \%$, $90 \%$, and $100 \%$ ethanol aqueous solutions were successively added to the wells for cell dehydration. The treated samples were observed under SEM after being sputter-coated with gold.

2.6.3. Cell Cytotoxicity Test. MG63 cells were seeded at a density of $4 \times 10^{4}$ cells/well in a 12 -well plate. The culture times of $1 \mathrm{~d}, 3 \mathrm{~d}$, and $5 \mathrm{~d}$ were chosen to observe the toxicity of samples. After being cultured for $1 \mathrm{~d}, 3 \mathrm{~d}$, and $5 \mathrm{~d}$ in a humidified atmosphere of $5 \% \mathrm{CO}_{2}, 10 \mu \mathrm{L}$ MTT $(5 \mathrm{~g} / \mathrm{L})$ was added to every well, and the cells continued to incubate for $4 \mathrm{~h}$ at $37^{\circ} \mathrm{C}$. After this, $1 \mathrm{~mL}$ DMSO was added to each well, and the 12-well plate was continuously oscillated for $10 \mathrm{~min}$ at $150 \mathrm{rpm}$. Then, the solution was transferred to a 96-well plate, and the absorbance was measured at $490 \mathrm{~nm}$ using a bioassay reader (HTS 7000 Plus, PerkinElmer Co., USA).

2.6.4. Cell Adhesion, Distribution, and Proliferation. The cell adhesion and distribution of all the prepared samples were evaluated by representative fluorescence microscopy images of MG63 cells. The samples were placed into a 12microwell plate and seeded with MG63 cells at a density of $1 \times 10^{4}$ cells/well. After 1 day of culture, the medium was extracted, and the samples were rinsed with PBS 3 times; then, $500 \mu \mathrm{L}$ paraformaldehyde (4\%) was put into each well to fix the cells on the samples for $30 \mathrm{~min}$. After extracting the paraformaldehyde, the attached cells were stained by fluorescein isothiocyanate (FITC, Sigma), which highlights the cytoskeletal protein (excitation max.: $490 \mathrm{~nm}$; emission max.: $520 \mathrm{~nm}$; Sigma, USA; $5 \mu \mathrm{g} / \mathrm{ml}$ of DMSO). This dye was applied for $30 \mathrm{~min}$ at room temperature. The microscopy images were acquired using an IX-51 microscope equipped with a digital camera (DP-70, Olympus, Japan).

After seeding for 1, 3, and 7 days, the MG63 cells on different samples were detached using a trypsin-EDTA solution (Sigma, USA, cat. number T4174) in PBS for $10 \mathrm{~min}$ at room temperature, and the number of cells was evaluated using a Vi-CELL XR analyzer (Beckman Coulter, USA). 


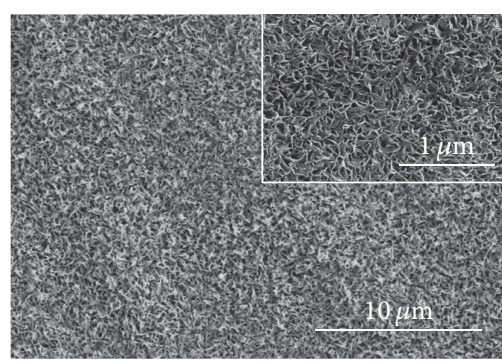

(a)

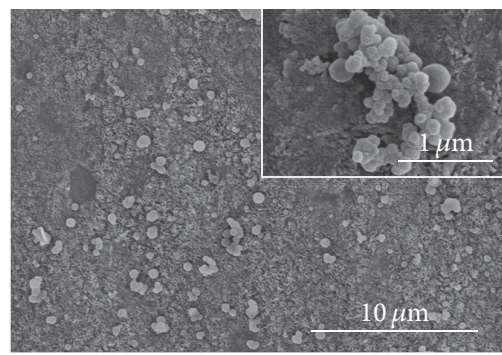

(d)

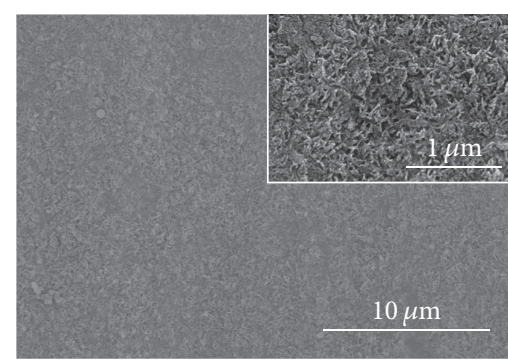

(b)

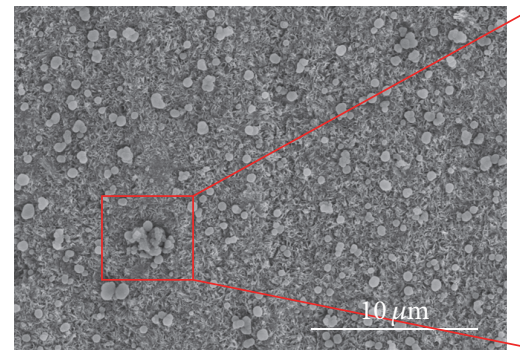

(e)

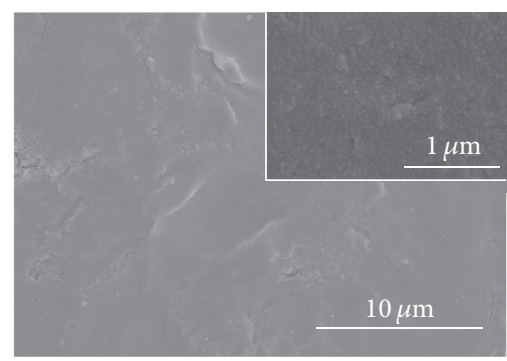

(c)

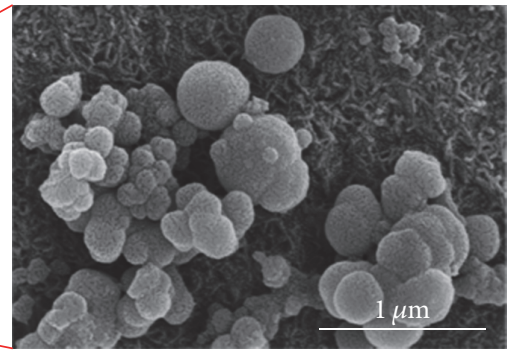

(f)

Figure 2: SEM images of the coatings: (a) Ti, (b) Ti/DOPA, (c) Ti/DOPA/SA, (d) Ti/DOPA/SA/Srl, (e) Ti/DOPA/SA/Sr5, and (f) partially enlarged view of Ti/DOPA/SA/Sr5 (scale bars: $10 \mu \mathrm{m}$ ).

2.6.5. Alkaline Phosphatase Activity. The MG63 cells were seeded onto samples at a density of $1 \times 10^{4}$ cells/well on a 12 microwell plate. After 3, 7, and 14 days of culture, the cultural medium was carefully extracted, and the coatings were gently washed twice with PBS. Then, $500 \mu \mathrm{L}$ of $0.2 \%$ (v/v) Triton X100 (Sigma, USA) was added to each well for lysis for $2 \mathrm{~h}$. After the solutions became homogeneous, $3 \mathrm{~mL}$ Coomassie Brilliant Blue staining solution, $0.6 \mathrm{~mL}$ cell lysis solution, and $0.4 \mathrm{~mL}$ double distilled water were added and mixed for $10 \mathrm{~min}$, and the OD value of the mixed solution was measured using an ELISA reader (Tecan, Austria) at $595 \mathrm{~nm}$. The protein concentration was determined with bovine serum albumin as a standard. Then, $100 \mu \mathrm{L}$ of the cell lysis solution and $100 \mu \mathrm{L}$ of $25 \mu \mathrm{g} / \mathrm{mL}$ p-nitrophenyl phosphate disodium salt were added to each well of a 96-well plate (6 wells in each group), after which the reaction was stopped by adding $50 \mu \mathrm{L} \mathrm{NaOH}(3 \mathrm{~mol} / \mathrm{L}), 100 \mu \mathrm{L}$ of $0.2 \%$ (v/v) Triton X-100, $100 \mu \mathrm{L}$ of $25 \mu \mathrm{g} / \mathrm{mL}$ PNPP. The $50 \mu \mathrm{L}$ of $3 \mathrm{~mol} / \mathrm{L} \mathrm{NaOH}$ was added to empty well as the blank control. The OD values were measured at $405 \mathrm{~nm}$, and the OD per milligram of protein was calculated.

2.7. Statistical Analysis. Numerical data was analyzed using standard ANOVA techniques, and statistical difference was considered at $p<0.05$. All the experiments were completed 5 times, with 3 replications used for each experiment.

\section{Results and Discussion}

3.1. Characterization of the Coatings. Figure 2 shows the surface morphologies of the synthesized samples. After acid and alkali treatment (Figure 2(a)), Ti had a surface with a dense and porous structure, which is beneficial for covalent bond grafting [31]. On Ti/DOPA (Figure 2(b)), it can be clearly observed that the dense and porous structure was covered. The results demonstrated that DOPA successfully bonded in the Ti surface and the poly(dopamine) formed a distinctive layer [32]. On Ti/DOPA/SA (Figure 2(c)), the surface appears flat, which may be attributed to the fluidity of the SA [23]. Figures 2(d) and 2(e) show that abundant spherical particles with a uniform distribution on the surface are formed. A similar morphology has been previously shown by Li et al. [33]. Many hydroxyl and carboxyl compounds in SA have the chelation of $\mathrm{Sr}^{2+}$; meanwhile, $\mathrm{Na}^{+}$can be substituted for $\mathrm{Sr}^{2+}$ to form strontium alginate, which presents in the form of a precipitate. Moreover, more spherical particles on Ti/DOPA/SA/Sr5 can be observed when compared with Ti/DOPA/SA/Srl; this also demonstrates that SA has good chelation of Sr.

Figure 3 shows the FT-IR spectra of the synthesized samples in the range of $4000-500 \mathrm{~cm}^{-1}$. The spectra of Ti (Figure 3(a)) look smooth except the peak emerging at $568 \mathrm{~cm}^{-1}$, which is ascribed to the Ti-O-Ti stretching mode of $\mathrm{TiO}_{2}[34,35]$. The main characteristic peaks of Ti/DOPA (Figure 3(b)) are at $3365 \mathrm{~cm}^{-1}\left(-\mathrm{NH}_{2}\right.$ stretching), $2939 \mathrm{~cm}^{-1}$ (- $\mathrm{CH}_{2}$ stretching), $1616 \mathrm{~cm}^{-1}$ (-C=O stretching), $1495 \mathrm{~cm}^{-1}$ ($\mathrm{CH}_{2}$ bending), and $577 \mathrm{~cm}^{-1}$ (Ti-O-Ti stretching) [36]. These emerging peaks indicate that DOPA is successfully coated on Ti. As shown in Figure 3(c), the alginate characteristic peaks of $-\mathrm{OH}$ stretching, - $\mathrm{CH}$ stretching, - $\mathrm{NH}$ stretching, $\mathrm{C}=\mathrm{O}$ stretching, $-\mathrm{CH}$ bending, and $-\mathrm{C}-\mathrm{O}-\mathrm{C}$ stretching are at $3530 \mathrm{~cm}^{-1}, 2939 \mathrm{~cm}^{-1}, 2243 \mathrm{~cm}^{-1}, 1627 \mathrm{~cm}^{-1}, 1416 \mathrm{~cm}^{-1}$, and $1100 \mathrm{~cm}^{-1}$, respectively [23,37]. Among these peaks, $2243 \mathrm{~cm}^{-1}$ (-NH stretching) is attributed to the acid amide bond that is produced through the reaction of the amino 


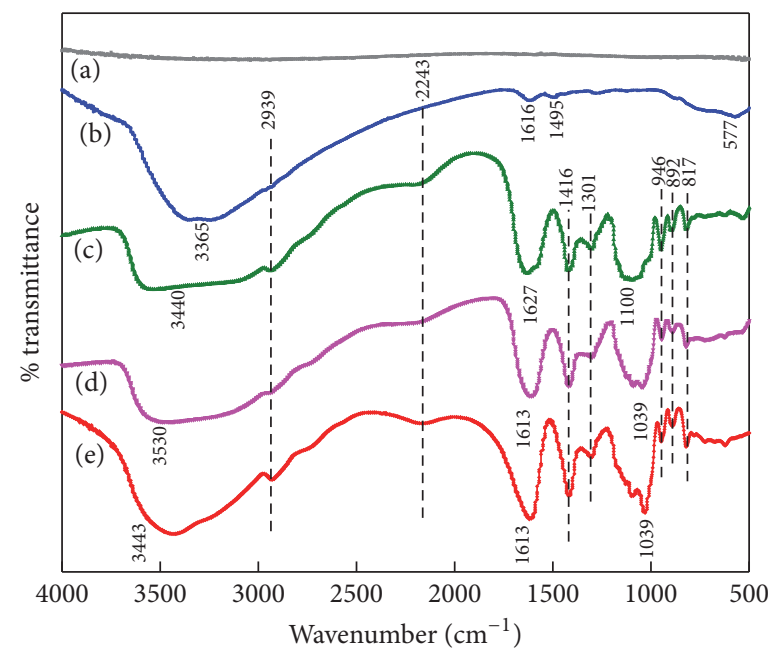

FIGURE 3: FT-IR spectra of the coatings: (a) Ti, (b) Ti/DOPA, (c) Ti/DOPA/SA, (d) Ti/DOPA/SA/Srl, and (e) Ti/DOPA/SA/Sr5.

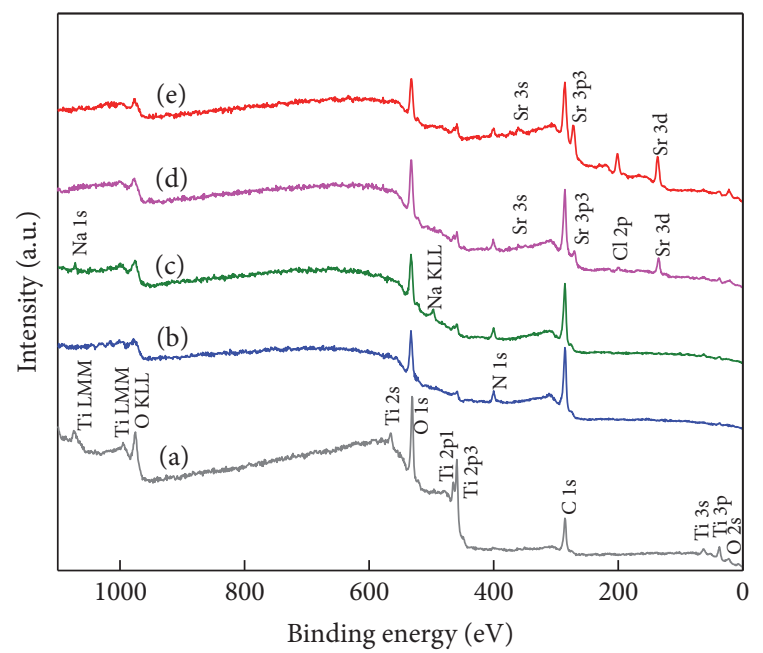

FIgURE 4: XPS spectra of the coatings: (a) Ti, (b) Ti/DOPA, (c) $\mathrm{Ti} / \mathrm{DOPA} / \mathrm{SA}$, (d) Ti/DOPA/SA/Srl, and (e) Ti/DOPA/SA/Sr5.

group in DOPA and the hydroxyl in SA, and the result demonstrates that the coating of SA is successfully prepared. As shown in Figures 3(d) and 3(e), the alginate characteristic peaks show little differences except that a part of the peaks shifted to a lower wavenumber, which is attributed to the polar molecule $\mathrm{SrCl}_{2}$ enhancing the vibrational frequency of the polar bonds $(-\mathrm{NH},>\mathrm{C}=\mathrm{O})$ [38].

The chemical compositions of the surface after a series of modifications are determined by XPS. The XPS spectra of the synthesized samples and their corresponding surface elemental compositions are shown in Figure 4 and Table 1. On pure $\mathrm{Ti}$ (Figure 4(a)), the predominate components are $\mathrm{C} 1 \mathrm{~s}$, $\mathrm{Ti} 2 \mathrm{p}$, and $\mathrm{O} 1 \mathrm{~s}$, and the binding energies of these peaks appear at $285 \mathrm{eV}, 460 \mathrm{eV}$, and $531 \mathrm{eV}$, respectively. Carbon is typically present in the wide-scan spectrum of pure $\mathrm{Ti}$ due to the unavoidable hydrocarbon contamination, and it is used as an internal reference at $284.6 \mathrm{eV}$ for calibrating peak positions

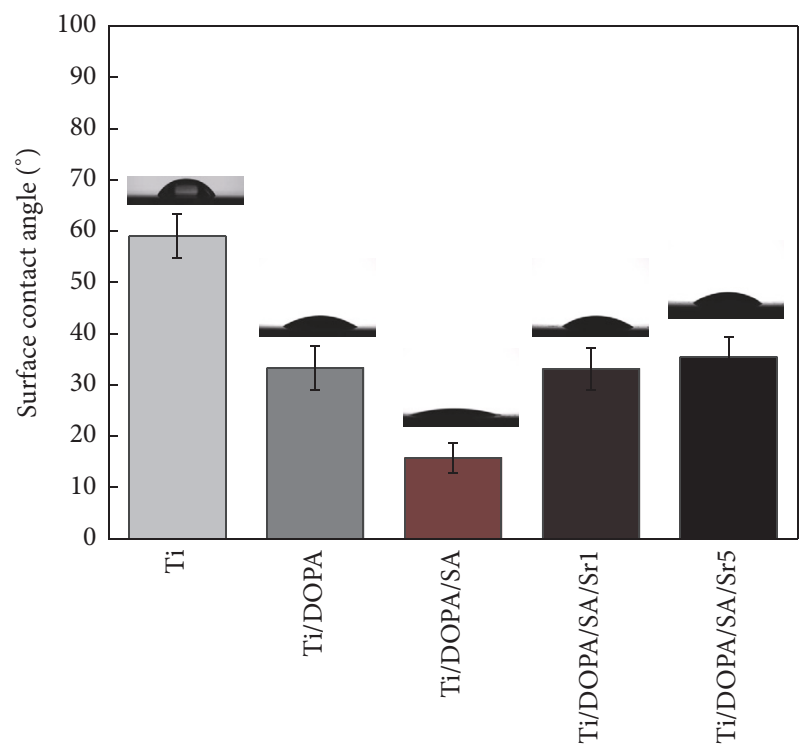

FIGURE 5: Water contact angles measured on various coatings.

[39]. On Ti/DOPA (Figure 4(b)), N 1s obviously emerges at $399 \mathrm{eV}$ for the amino group in the DOPA. As shown in Table 1, the increase in the $\mathrm{N}$ and $\mathrm{C}$ contents and the decrease in the $\mathrm{Ti}$ content indicate the successful anchoring of dopamine on Ti. The carbon-to-nitrogen $(\mathrm{C} / \mathrm{N})$ ratio $(10.44)$ for $\mathrm{Ti} / \mathrm{DOPA}$ is higher than the dopamine (8.0), which is probably attributed to the surface carbon contamination of $\mathrm{Ti}$. The increase in $\mathrm{C}$ 1s and $\mathrm{O}$ 1s signals coupled with the decrease in the $\mathrm{Ti} 2 \mathrm{p}$ signal is further accentuated on Ti/DOPA/SA (Figure $4(\mathrm{c})$ ), indicating the success of the grafting process. On Ti/DOPA/SA/Srl (Figure 4(d)), the predominant peaks of Sr appear at $135 \mathrm{eV}$ (Sr 3d), $270 \mathrm{eV}$ (Sr 3p3), and $360 \mathrm{eV}$ (Sr 3s), and the content of $\mathrm{Sr}$ is $2.6 \%$ (Table 1). It proves the success of the preparation of the $\mathrm{Sr}$ coating via chelating with SA. The peak of $\mathrm{Sr}$ is apparent, and the Sr content achieves $5.5 \%$ on $\mathrm{Ti} / \mathrm{DOPA} / \mathrm{SA} / \mathrm{Sr} 5$. Therefore, the concentration of Sr in the Sr coating will increase accordingly with the improvement of $\mathrm{Sr}^{2+}$ concentration within $5 \mathrm{wt} . \%$. This suggests that SA has good chelation of $\mathrm{Sr}$ when the $\mathrm{Sr}$ concentration is relatively low.

Figure 5 shows the contact angle of the synthesized samples. The water contact angles on Ti/DOPA, Ti/DOPA/SA, $\mathrm{Ti} / \mathrm{DOPA} / \mathrm{SA} / \mathrm{Sr} 1$, and Ti/DOPA/SA/Sr5 are $33.26^{\circ} \pm 4.35^{\circ}$, $15.71 \pm 4.12^{\circ}, 33.08^{\circ} \pm 3.65^{\circ}$, and $35.40^{\circ} \pm 1.68^{\circ}$, respectively, which are significantly smaller than that on pure $\mathrm{Ti}$ $\left(59.00^{\circ} \pm 6.12^{\circ}\right)$. This suggests that the surface modification can effectively improve the surface hydrophilicity of Ti. The hydrophilic quality of Ti/DOPA/SA, with the smallest contact angle among the synthesized samples, is obviously superior to the other coatings. This is because much of the hydroxyl presents as hydrophilic in the SA. When compared with Ti/DOPA/SA, the contact angles of Ti/DOPA/SA/Sr1 and $\mathrm{Ti} / \mathrm{DOPA} / \mathrm{SA} / \mathrm{Sr} 5$ demonstrate a significant increase, and this suggests that the coating of $\mathrm{Sr}$ is successfully prepared. Water contact angle measurement can also provide 
TABLE 1: Elemental composition at the surface of pristine and functionalized Ti substrates as determined by XPS.

\begin{tabular}{lcccrr}
\hline Substrate & $\mathrm{C} \%$ & $\mathrm{O} \%$ & $\mathrm{Ti} \%$ & $\mathrm{~N} \%$ & - \\
$\mathrm{Ti}$ & $42.6 \pm 0.46$ & $41.8 \pm 0.57$ & $15.6 \pm 0.74$ & - & - \\
$\mathrm{Ti} / \mathrm{DOPA}$ & $63.7 \pm 0.58$ & $21.5 \pm 0.49$ & $8.7 \pm 0.68$ & $6.1 \pm 0.56$ & - \\
$\mathrm{Ti} / \mathrm{DOPA} / \mathrm{SA}$ & $66.5 \pm 0.23$ & $24.7 \pm 0.28$ & $2.0 \pm 0.78$ & $6.8 \pm 0.50$ & - \\
$\mathrm{Ti} / \mathrm{DOPA} / \mathrm{SA} / \mathrm{Sr} 1$ & $66.0 \pm 0.48$ & $24.5 \pm 0.72$ & $2.1 \pm 0.38$ & $4.8 \pm 0.39$ & $2.6 \pm 0.82$ \\
$\mathrm{Ti} / \mathrm{DOPA} / \mathrm{SA} / \mathrm{Sr} 5$ & $64.6 \pm 0.39$ & $23.6 \pm 0.61$ & $1.7 \pm 0.45$ & $4.6 \pm 0.51$ & $5.5 \pm 0.76$ \\
\hline
\end{tabular}

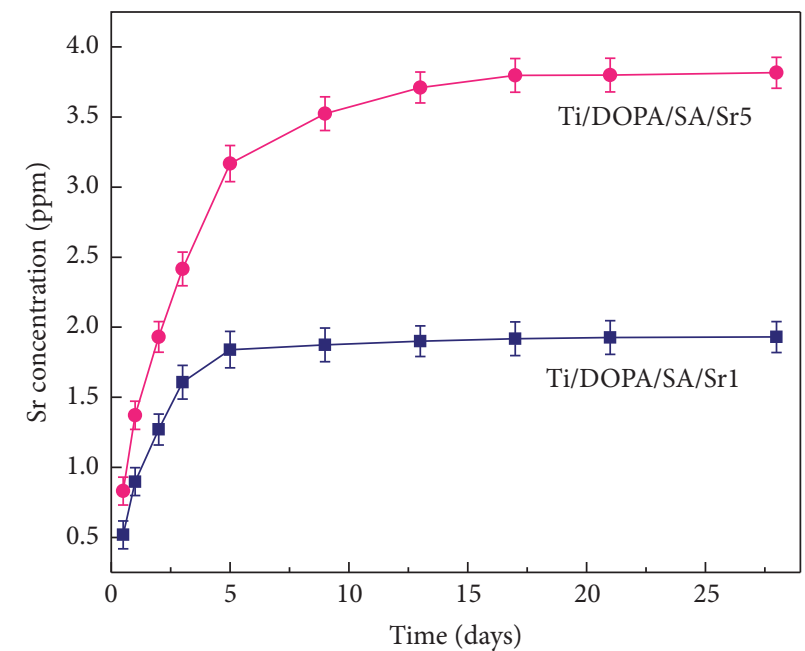

(a)

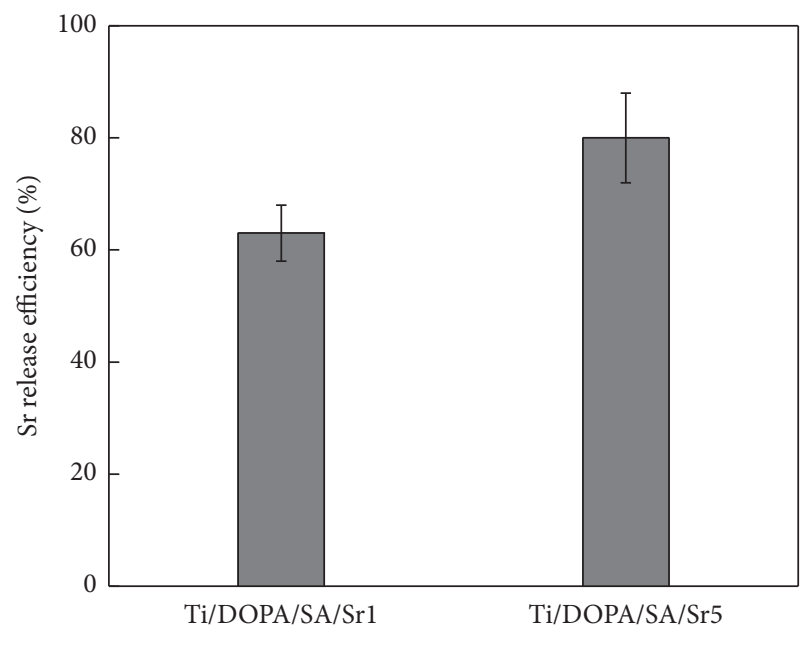

(b)

FIGURE 6: (a) Cumulative $\mathrm{Sr}^{2+}$ concentration of Ti/DOPA/SA/Sr1 and Ti/DOPA/SA/Sr5 as a function of time; (b) the Sr ${ }^{2+}$ release efficiency of Ti/DOPA/SA/Srl and Ti/DOPA/SA/Sr5 as a function of time.

supporting evidence that the Ti surface has been successfully modified.

3.2. $\mathrm{Sr}^{2+}$ Release Studies. The $\mathrm{Sr}^{2+}$ release behavior was assessed by immersing Ti/DOPA/SA/Sr1 and Ti/DOPA/SA/Sr5 in $5 \mathrm{~mL}$ PBS for up to 28 days. The $\mathrm{Sr}^{2+}$ release characteristics of $\mathrm{Ti} / \mathrm{DOPA} / \mathrm{SA} / \mathrm{Sr} 1$ and $\mathrm{Ti} / \mathrm{DOPA} / \mathrm{SA} / \mathrm{Sr} 5$ are presented in Figure 6. The release behavior can be described in 2 stages: a rapid burst and a slow release. In Figure 6(a), $\mathrm{Sr}^{2+}$ provides rapid burst from the alginate gel over the first 5 days. The average $\mathrm{Sr}^{2+}$ amounts released from Ti/DOPA/SA/Sr1 and Ti/DOPA/SA/Sr5 are $1.839 \mathrm{ppm}$ and $3.168 \mathrm{ppm}$, respectively. The rapid burst may be attributed to the electrostatic deposition of a part of $\mathrm{Sr}^{2+}$ [2]. A stage of slow release is followed by rapid burst, and $\mathrm{Sr}^{2+}$ release gradually diminishes over 5-28 days. The average $\mathrm{Sr}^{2+}$ concentration released from Ti/DOPA/SA/Srl and Ti/DOPA/SA/Sr5 was reached at $1.930 \mathrm{ppm}$ and $3.817 \mathrm{ppm}$, respectively, on the 28th day. The slow release of $\mathrm{Sr}$ is mainly due to the part of $\mathrm{Sr}^{2+}$ existing in the form of chelation with sodium alginate, and the covalent bond generated by chelation also plays an important role in the slow release.

At the early stage of implantation, the bone graft materials show rapid burst, which is beneficial in increasing the concentration of $\mathrm{Sr}^{2+}$ in the local area of the bone graft materials and makes them exhibit effective osteogenic activity. With the prolongation of soaking time, $\mathrm{Sr}^{2+}$ shows a slow release. The sustained release up to 1 month could promote $\mathrm{Sr}^{2+}$ in demonstrating osteogenic activity with long-term effectiveness in vivo $[22,40]$. The sodium alginate chelating with $\mathrm{Sr}^{2+}$ shows a considerably extended overall $\mathrm{Sr}$ release, confirming the ability of this approach to achieve a long and sustained Sr release, which may be required for effective bone therapy.

3.3. Loading Efficiency of $\mathrm{Sr}^{2+}$. After the Sr release assay, the loading efficiency of $\mathrm{Sr}$ was evaluated. The loading efficiency was calculated from the formula $\eta=m_{1} /\left(m_{1}+m_{r}\right)$, where $\eta$ is the loading efficiency, $m_{1}$ is the amount of the total release of $\mathrm{Sr}$, and $m_{r}$ is the amount of $\mathrm{Sr}$ in the rinse solution $[41,42]$. Figure 6(b) shows the loading efficiency of $\mathrm{Ti} / \mathrm{DOPA} / \mathrm{SA} / \mathrm{Sr}$ and $\mathrm{Ti} / \mathrm{DOPA} / \mathrm{SA} / \mathrm{Sr} 5$. The results indicate that approximately $60 \%-80 \%$ of $\mathrm{Sr}$ was retained on the surface of Ti/DOPA/SA/Srl and Ti/DOPA/SA/Sr5 after an initial wash.

3.4. Cell Morphology. Cellular activities that demonstrate the enhancement of MG63 cell functions consist of cell spreading, proliferation, increased enzyme production (ALP), and 


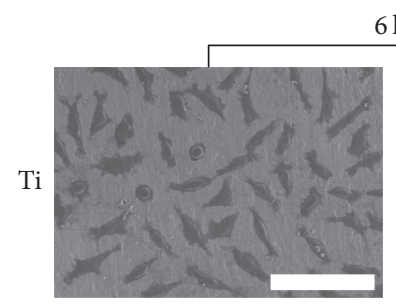

(a)

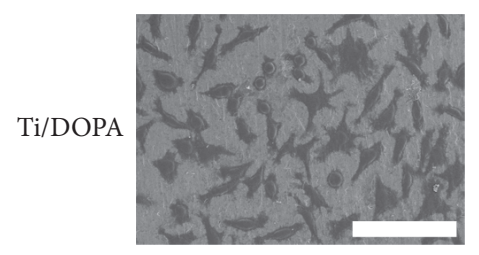

(c)

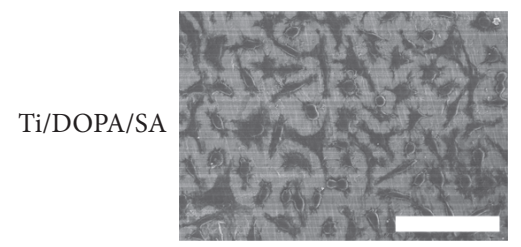

(e)

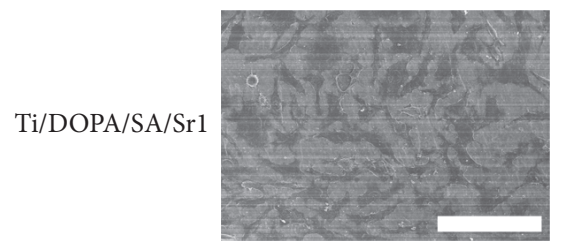

(g)

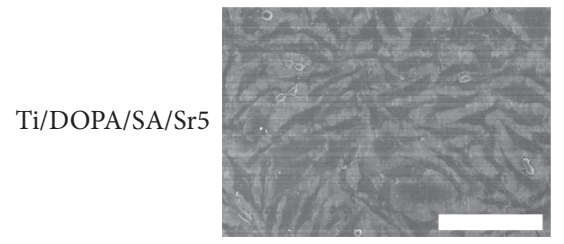

(i)

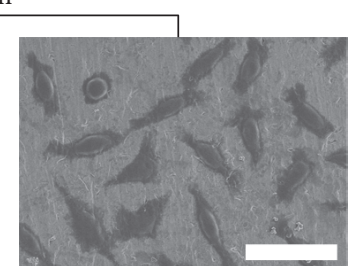

$\left(a_{1}\right)$

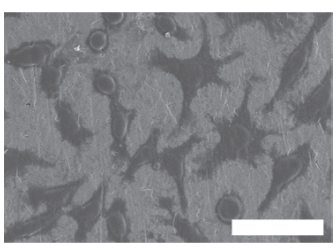

$\left(c_{1}\right)$

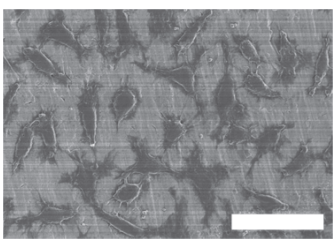

$\left(e_{1}\right)$

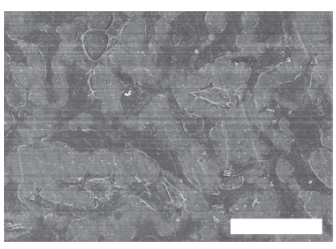

$\left(g_{1}\right)$

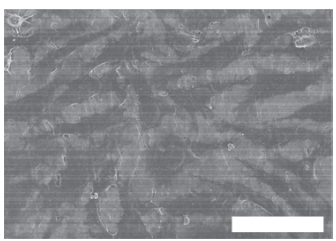

$\left(\mathrm{i}_{1}\right)$

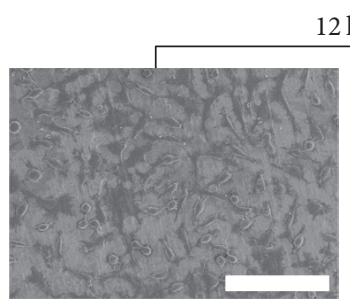

(b)

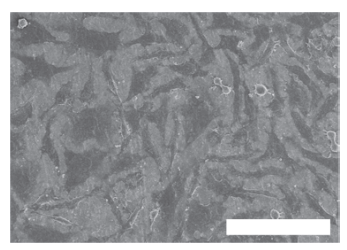

(d)

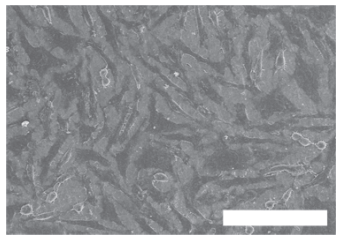

(f)

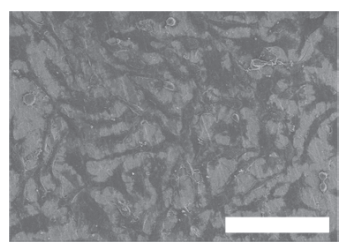

(h)

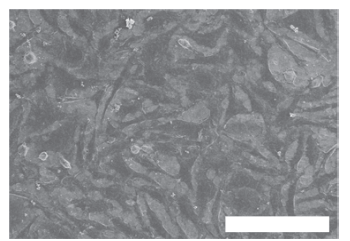

(j)

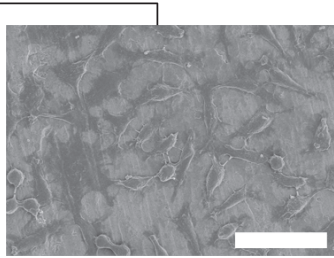

$\left(b_{1}\right)$

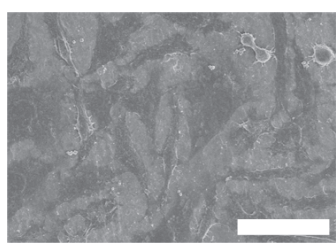

$\left(d_{1}\right)$

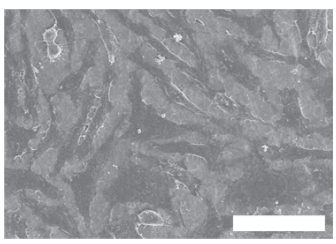

$\left(f_{1}\right)$

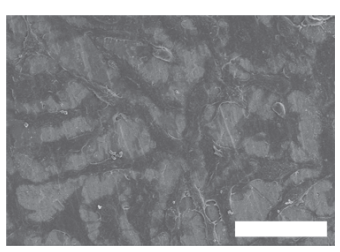

$\left(\mathrm{h}_{1}\right)$

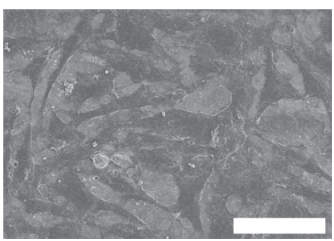

$\left(\mathrm{j}_{1}\right)$

FIGURE 7: SEM images of cells after $6 \mathrm{~h}$ and $12 \mathrm{~h}$ of culture on different samples: (a, b) Ti, (c, d) Ti/DOPA, (e, f) Ti/DOPA/SA, (g, h) Ti/DOPA/SA/Srl, and (i, k) Ti/DOPA/SA/Sr5 (scale bars: $100 \mu \mathrm{m}) ;\left(\mathrm{a}_{1}, \mathrm{~b}_{1}\right) \mathrm{Ti},\left(\mathrm{c}_{1}, \mathrm{~d}_{1}\right) \mathrm{Ti} / \mathrm{DOPA},\left(\mathrm{e}_{1}, \mathrm{f}_{1}\right) \mathrm{Ti} / \mathrm{DOPA} / \mathrm{SA},\left(\mathrm{g}_{1}, \mathrm{~h}_{1}\right)$ Ti/DOPA/SA/Srl, and $\left(\mathrm{i}_{1}, \mathrm{k}_{1}\right)$ Ti/DOPA/SA/Sr5 (scale bars: $\left.50 \mu \mathrm{m}\right)$.

mineralization (calcium deposition) [43, 44]. The attachment of MG63 cells to Ti is a prerequisite for the further cellular functions that lead to successful osseointegration of the implant in vivo [45]. Figure 7 shows the MG63 cells on various samples after seeding for $6 \mathrm{~h}$ and $12 \mathrm{~h}$. On pure Ti (Figures $7(\mathrm{a})$ and $7\left(\mathrm{a}_{1}\right)$ ), most of the MG63 cells remain as isolated and rounded single cells at $6 \mathrm{~h}$. The behavior of the MG63 cells on Ti/DOPA (Figures $7(\mathrm{c})$ and $7\left(c_{1}\right)$ ) and Ti/DOPA/SA (Figures $7(\mathrm{e})$ and $7\left(\mathrm{e}_{1}\right)$ ) is similar to that observed on pure Ti. On Ti/DOPA/SA/Srl (Figures $7(\mathrm{~g})$ and $\left.7\left(\mathrm{~g}_{1}\right)\right)$ and Ti/DOPA/SA/Sr5 (Figures $7(\mathrm{i})$ and $7\left(\mathrm{i}_{1}\right)$ ), however, dramatic difference can be observed, in that almost each cell spreads and links up to other cells. Panzavolta et al. [46] showed that $\mathrm{Sr}^{2+}$ incorporation has a slightly positive effect on early cellular attachment. This result is consistent with our findings. After $12 \mathrm{~h}$ cultivation (Figures $7(\mathrm{~b})$ and $7\left(\mathrm{~b}_{1}\right)$ ), the MG63 cells did not spread completely on pure Ti. After DOPA and SA functionalization (Figures $7(\mathrm{~d})-7\left(\mathrm{~d}_{1}\right)$ and Figures $\left.7(f)-7\left(f_{1}\right)\right)$, it can be seen that the spreading of MG63 cells increased. On Ti/DOPA/SA/Sr1 and Ti/DOPA/SA/Sr5 (Figures $7(\mathrm{~h})-7\left(\mathrm{~h}_{1}\right)$ and Figures $\left.7(\mathrm{k})-7\left(\mathrm{k}_{1}\right)\right)$, the number of attached cells was significantly higher. When compared with $\mathrm{Ti} / \mathrm{DOPA} / \mathrm{SA} / \mathrm{Srl}$, further improvement of the cell number on Ti/DOPA/SA/Sr5 is attributed to $\mathrm{Sr}^{2+}$ incorporation. The current study definitively confirms the robust effect of $\mathrm{Sr}^{2+}$ incorporation on the adhesion and spreading of MG63 cells. 


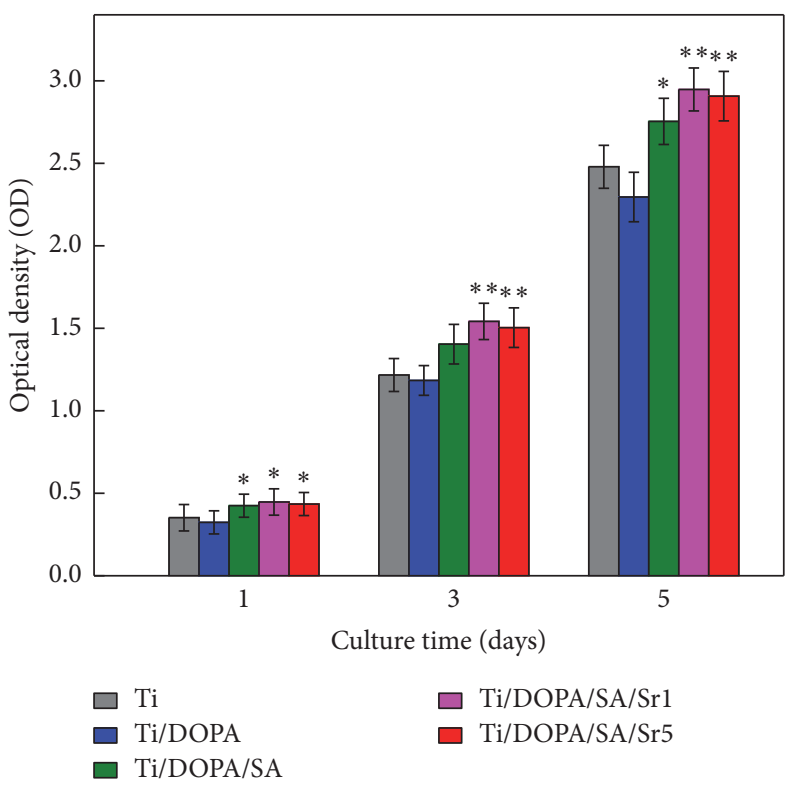

FIGURE 8: Cell viability of MG63 cells cultured for different periods of time on Ti, Ti/DOPA, Ti/DOPA/SA, Ti/DOPA/SA/Srl, and $\mathrm{Ti} / \mathrm{DOPA} / \mathrm{SA} / \mathrm{Sr} 5\left({ }^{*} p<0.05\right.$ compared with $\mathrm{Ti} ;{ }^{* *} p<0.01$ compared with Ti).

3.5. In Vitro Cytotoxicity. Cell viability was evaluated by the performed MTT assay. Figure 8 shows the MTT test result with the culture time of $1 \mathrm{~d}, 3 \mathrm{~d}$, and $5 \mathrm{~d}$ at a density of $4 \times$ $10^{4}$ cells/well in a 12-well plate. As shown in Figure 8, the cell viabilities on $\mathrm{Ti}$ and Ti/DOPA are comparatively low. Higher proliferation on Ti/DOPA/SA than that on Ti can be seen, which may be attributed to the excellent biocompatibility of SA [47]. It is generally believed that a large enough quantity of hydroxyl in SA could increase MG63 cell proliferation [48]. Both Ti/DOPA/SA/Sr1 and Ti/DOPA/SA/Sr5 showed comparatively more enhancement compared to that on Ti. The results obtained in the current study demonstrate that SA incorporated with $\mathrm{Sr}^{2+}$ could be more biocompatible.

3.6. Cell Adhesion, Proliferation, and Alkaline Phosphatase Activity. Representative fluorescence microscopy images of the MG63 cells after $24 \mathrm{~h}$ cultivation were investigated to analyze the cell growth states on different samples. As shown in Figures 9(a)-9(j), the MG63 cells grew well on different samples. When compared with pure Ti (Figure 9(a)), Ti/DOPA (Figure 9(b)) has a relatively lower cell density. With the attached $\mathrm{Sr}^{2+}$ (Figures 9(e) and 9(f)), it can be seen that the spreading and the density of MG63 cells significantly increased. The results are consistent with the SEM.

The effect of surface functionalization on the proliferation of MG63 cells at days 1, 3, and 7 is shown in Figure 9(k). When compared with pure Ti, Ti/DOPA had a slight trend towards decreased proliferation and Ti/DOPA/SA showed no significant enhancement. However, on Ti/DOPA/SA/Sr1 and Ti/DOPA/SA/Sr5, significantly greater enhancement was exhibited on the proliferation than in the samples without Sr. With an increasing concentration of $\mathrm{Sr}^{2+}$, continuous enhancement can be observed. It indicates that the larger amount of released $\mathrm{Sr}^{2+}$ is in the safe dosage range [49].
ALP activity, which is widely used as a marker for early differentiation of osteoblast-like cells, is an important consideration for enhanced osseointegration besides the initial cell adhesion and proliferation [42, 50]. ALP activity was measured after the cells were cultured for 3, 7, and 14 days on different samples. As shown in Figure 9(1), ALP activities of MG63 cells cultured for 3 days on Ti, Ti/DOPA, and Ti/DOPA/SA were at a similar level. Both the ALP activities on Ti/DOPA/SA/Srl and Ti/DOPA/SA/Sr5 presented a slightly increased trend. When cultured for 7 days, the ALP activities of MG63 cells cultured on Ti/DOPA/SA/Sr1 and Ti/DOPA/SA/Sr5 presented significantly higher improvement than that on Ti. More significant improvement can be seen when MG63 cells were cultured for 14 days. A previous study showed that $\mathrm{Sr}$ can directly interact with the Ca-sensing receptor to enter into osteoblast cells and trigger mitogenic signals [51]. Figure 9(1) supports the notion that the Sr can stimulate MG63 cell differentiation and enhance the ALP activity.

\section{Conclusion}

A Sr-incorporated coating on a Ti surface was successfully fabricated by electrostatic immobilization and chemical bond grafting. With its excellent biocompatibility and stability, SA was selected as the suitable stabilizing agent to realize the uniform distribution of Sr. Long-lasting and controllable $\mathrm{Sr}$ release was observed on the Ti/DOPA/SA/Srl and Ti/DOPA/SA/Sr5 samples. Sr incorporation showed effectiveness on the adhesion, cytotoxicity, proliferation, and ALP activity. A higher Sr content resulted in more effective functioning in terms of promoting the osteogenic activity of MG63 cells. Such Sr-incorporated coatings could provide a promising solution for promoting the tissue integration of 


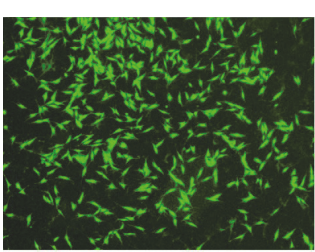

(a)

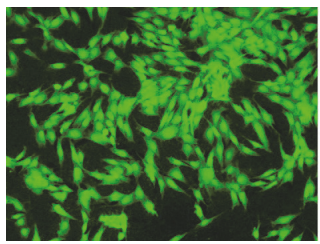

(f)

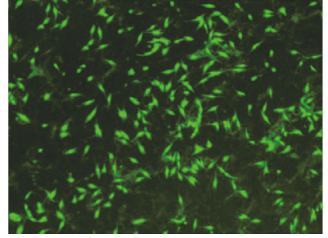

(b)

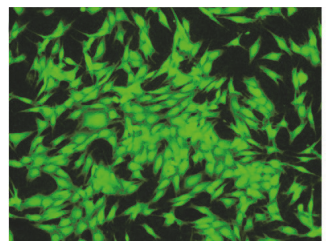

(g)

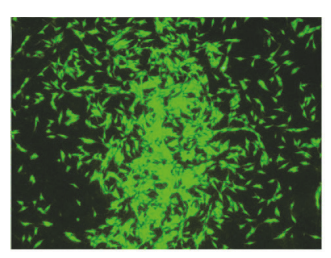

(c)

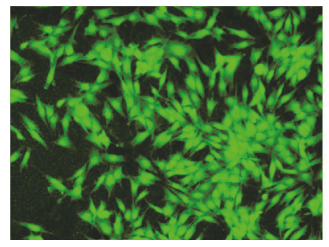

(h)

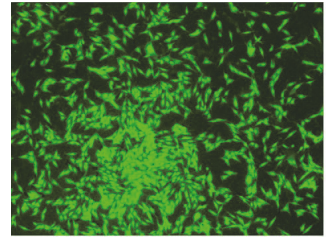

(d)

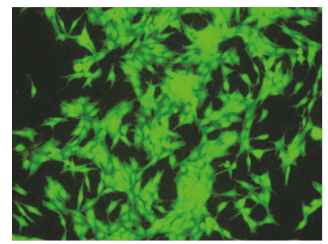

(i)

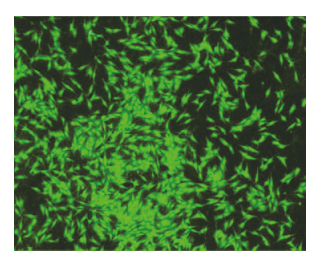

(e)

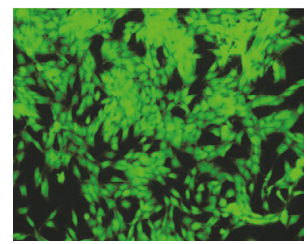

(j)

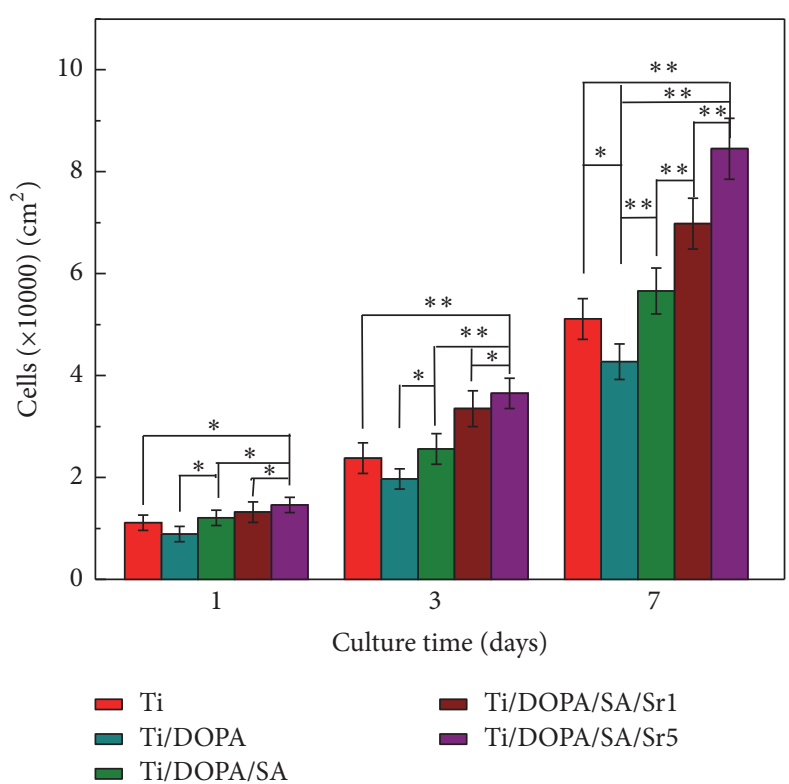

(k)

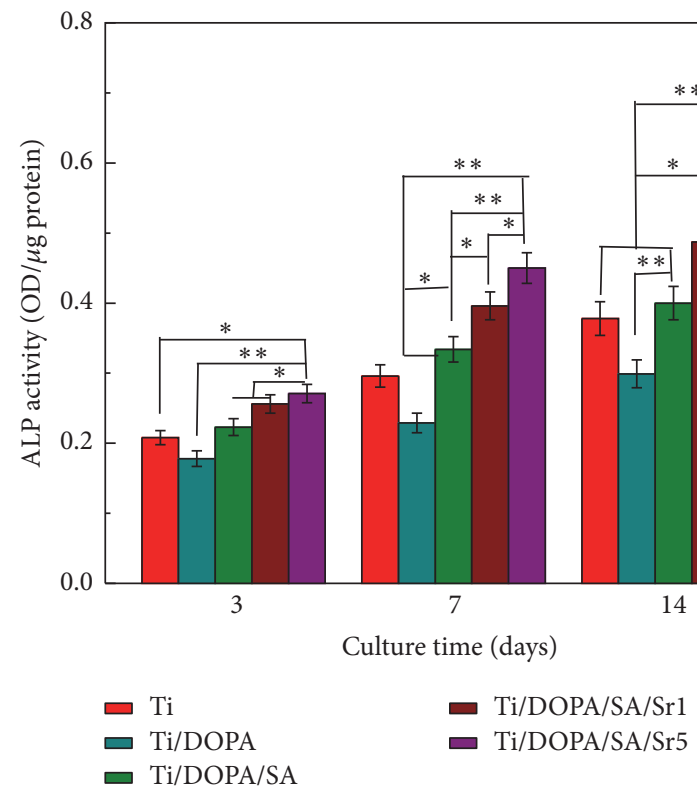

(l)

Figure 9: MG63 cells adhesion and distribution after 1 day of incubation. (a, f) Ti, (b, g) Ti/DOPA, (c, h) Ti/DOPA/SA, (d, i) Ti/DOPA/SA/Sr1, and $(e, j)$ Ti/DOPA/SA/Sr5 ((a-e: magnified 40 times); (f-j: magnified 100 times)). (k) Cell proliferation measured by counting under a fluorescence microscope after 1, 3, and 7 days of incubation. (1) ALP activity of MG63 cells after 3, 7, and 14 days of incubation. Statistically significant differences $\left({ }^{*} p<0.05\right.$ and $\left.{ }^{* *} p<0.01\right)$.

implants; thus, they have considerable potential for use as bone substitutes in orthopedic applications.

\section{Disclosure}

Ning Yuan and Lili Jia are co-first authors.

\section{Conflicts of Interest}

The authors declare that they have no conflicts of interest.

\section{Authors' Contributions}

Ning Yuan and Lili Jia contributed equally to this work.

\section{Acknowledgments}

This work was financially supported by the National Natural Science Foundation of China (Grant no. 31570970) and Tianjin Research Program of Application Foundation and Advanced Technology (14JCQNJC03100).

\section{References}

[1] P.-H. Chua, K.-G. Neoh, E.-T. Kang, and W. Wang, "Surface functionalization of titanium with hyaluronic acid/chitosan polyelectrolyte multilayers and RGD for promoting osteoblast functions and inhibiting bacterial adhesion," Biomaterials, vol. 29, no. 10, pp. 1412-1421, 2008.

[2] K. Gulati, S. Ramakrishnan, M. S. Aw, G. J. Atkins, D. M. Findlay, and D. Losic, "Biocompatible polymer coating of titania 
nanotube arrays for improved drug elution and osteoblast adhesion," Acta Biomaterialia, vol. 8, no. 1, pp. 449-456, 2012.

[3] S. Mei, H. Wang, W. Wang et al., "Antibacterial effects and biocompatibility of titanium surfaces with graded silver incorporation in titania nanotubes," Biomaterials, vol. 35, no. 14, pp. 4255-4265, 2014.

[4] Z. Shi, K. G. Neoh, E. T. Kang, K. P. Chye, and W. Wang, "Surface functionalization of titanium with carboxymethyl chitosan and immobilized bone morphogenetic protein- 2 for enhanced osseointegration," Biomacromolecules, vol. 10, no. 6, pp. 16031611, 2009.

[5] H. S. Alghamdi, R. Bosco, J. J. J. P. van den Beucken, X. F. Walboomers, and J. A. Jansen, "Osteogenicity of titanium implants coated with calcium phosphate or collagen type-I in osteoporotic rats," Biomaterials, vol. 34, no. 15, pp. 3747-3757, 2013.

[6] D. A. Puleo and A. Nanci, "Understanding and controlling the bone-implant interface," Biomaterials, vol. 20, no. 23-24, pp. 2311-2321, 1999.

[7] J.-W. Park, H.-K. Kim, Y.-J. Kim, J.-H. Jang, H. Song, and T. Hanawa, "Osteoblast response and osseointegration of a Ti-6Al$4 \mathrm{~V}$ alloy implant incorporating strontium," Acta Biomaterialia, vol. 6, no. 7, pp. 2843-2851, 2010.

[8] C. Wu, Z. Chen, Q. Wu et al., "Clinoenstatite coatings have high bonding strength, bioactive ion release, and osteoimmunomodulatory effects that enhance in vivo osseointegration," Biomaterials, vol. 71, Article ID 17022, pp. 35-47, 2015.

[9] K. L. Wong, C. T. Wong, W. C. Liu et al., "Mechanical properties and in vitro response of strontium-containing hydroxyapatite/polyetheretherketone composites," Biomaterials, vol. 30, no. 23-24, pp. 3810-3817, 2009.

[10] J. Zhou, B. Li, S. Lu, L. Zhang, and Y. Han, "Regulation of osteoblast proliferation and differentiation by interrod spacing of Sr-HA nanorods on microporous titania coatings," ACS Applied Materials and Interfaces, vol. 5, no. 11, pp. 5358-5365, 2013.

[11] P. J. Marie, P. Ammann, G. Boivin, and C. Rey, "Mechanisms of action and therapeutic potential of strontium in bone," Calcified Tissue International, vol. 69, no. 3, pp. 121-129, 2001.

[12] M. Schumacher, A. Lode, A. Helth, and M. Gelinsky, "A novel strontium(II)-modified calcium phosphate bone cement stimulates human-bone-marrow-derived mesenchymal stem cell proliferation and osteogenic differentiation in vitro," Acta Biomaterialia, vol. 9, no. 12, pp. 9547-9557, 2013.

[13] G. X. Ni, K. Y. Chiu, W. W. Lu et al., "Strontium-containing hydroxyapatite bioactive bone cement in revision hip arthroplasty," Biomaterials, vol. 27, no. 24, pp. 4348-4355, 2006.

[14] S. K. Tat, J.-P. Pelletier, F. Mineau, J. Caron, and J. MartelPelletier, "Strontium ranelate inhibits key factors affecting bone remodeling in human osteoarthritic subchondral bone osteoblasts," Bone, vol. 49, no. 3, pp. 559-567, 2011.

[15] E. Bonnelye, A. Chabadel, F. Saltel, and P. Jurdic, "Dual effect of strontium ranelate: Stimulation of osteoblast differentiation and inhibition of osteoclast formation and resorption in vitro," Bone, vol. 42, no. 1, pp. 129-138, 2008.

[16] C. Capuccini, P. Torricelli, F. Sima et al., "Strontium-substituted hydroxyapatite coatings synthesized by pulsed-laser deposition: in vitro osteoblast and osteoclast response," Acta Biomaterialia, vol. 4, no. 6, pp. 1885-1893, 2008.

[17] Y. Li, Q. Li, S. Zhu et al., "The effect of strontium-substituted hydroxyapatite coating on implant fixation in ovariectomized rats," Biomaterials, vol. 31, no. 34, pp. 9006-9014, 2010.
[18] L. Zhao, H. Wang, K. Huo et al., "The osteogenic activity of strontium loaded titania nanotube arrays on titanium substrates," Biomaterials, vol. 34, no. 1, pp. 19-29, 2013.

[19] C. Lindahl, S. Pujari-Palmer, A. Hoess, M. Ott, H. Engqvist, and W. Xia, "The influence of Sr content in calcium phosphate coatings," Materials Science and Engineering C, vol. 53, pp. 322330, 2015.

[20] I. Schrooten, G. J. S. Behets, W. E. Cabrera et al., "Dosedependent effects of strontium on bone of chronic renal failure rats," Kidney International, vol. 63, no. 3, pp. 927-935, 2003.

[21] H. Zreiqat, Y. Ramaswamy, C. Wu et al., "The incorporation of strontium and zinc into a calcium-silicon ceramic for bone tissue engineering," Biomaterials, vol. 31, no. 12, pp. 3175-3184, 2010.

[22] E. Gentleman, Y. C. Fredholm, G. Jell et al., "The effects of strontium-substituted bioactive glasses on osteoblasts and osteoclasts in vitro," Biomaterials, vol. 31, no. 14, pp. 3949-3956, 2010.

[23] Y. Xin, J. Jiang, K. Huo, T. Hu, and P. K. Chu, "Bioactive SrTiO3 nanotube arrays: strontium delivery platform on Tibased osteoporotic bone implants," ACS Nano, vol. 3, no. 10, pp. 3228-3234, 2009.

[24] L. Fuks, A. Oszczak, E. Gniazdowska, and D. Sternik, "Calcium alginate and chitosan as potential sorbents for strontium radionuclide," Journal of Radioanalytical and Nuclear Chemistry, vol. 304, no. 1, pp. 15-20, 2015.

[25] E. S. Place, L. Rojo, E. Gentleman, J. P. Sardinha, and M. M. Stevens, "Strontium-and zinc-alginate hydrogels for bone tissue engineering," Tissue Engineering A, vol. 17, no. 21-22, pp. 2713$2722,2011$.

[26] X. Zhang, Z. Li, X. Yuan et al., "Cytotoxicity and antibacterial property of titanium alloy coated with silver nanoparticlecontaining polyelectrolyte multilayer," Materials Science and Engineering C, vol. 33, no. 5, pp. 2816-2820, 2013.

[27] G. Orive, S. Ponce, R. M. Hernández, A. R. Gascón, M. Igartua, and J. L. Pedraz, "Biocompatibility of microcapsules for cell immobilization elaborated with different type of alginates," Biomaterials, vol. 23, no. 18, pp. 3825-3831, 2002.

[28] H. Lee, S. M. Dellatore, W. M. Miller, and P. B. Messersmith, "Mussel-inspired surface chemistry for multifunctional coatings," Science, vol. 318, no. 5849, pp. 426-430, 2007.

[29] R. A. Zangmeister, T. A. Morris, and M. J. Tarlov, "Characterization of polydopamine thin films deposited at short times by autoxidation of dopamine," Langmuir, vol. 29, no. 27, pp. 86198628, 2013.

[30] N. F. Della Vecchia, A. Luchini, A. Napolitano et al., "Tris buffer modulates polydopamine growth, aggregation, and paramagnetic properties," Langmuir, vol. 30, no. 32, pp. 9811-9818, 2014.

[31] F. Sun, H. Zhou, and J. Lee, "Various preparation methods of highly porous hydroxyapatite/polymer nanoscale biocomposites for bone regeneration," Acta Biomaterialia, vol. 7, no. 11, pp. 3813-3828, 2011.

[32] J. Kang, S. Tada, T. Kitajima, T. I. Son, T. Aigaki, and Y. Ito, "Immobilization of bone morphogenetic protein on DOPAor dopamine-treated titanium surfaces to enhance osseointegration," BioMed Research International, vol. 2013, Article ID 265980, 6 pages, 2013.

[33] B. Li, H. Liu, X. Ye, S. Li, and Z. Wu, "Rubidium and Cesium Ion Adsorption by a Potassium Titanium Silicate-Calcium Alginate Composite Adsorbent," Separation Science and Technology (Philadelphia), vol. 49, no. 7, pp. 1076-1085, 2014. 
[34] Y. Q. Liang, Z. D. Cui, S. L. Zhu, and X. J. Yang, "Characterization of self-organized $\mathrm{TiO}_{2}$ nanotubes on Ti-4Zr-22Nb-2Sn alloys and the application in drug delivery system," Journal of Materials Science: Materials in Medicine, vol. 22, no. 3, pp. 461467, 2011.

[35] Z. Li, B. Hou, Y. Xu, D. Wu, and Y. Sun, "Hydrothermal synthesis, characterization, and photocatalytic performance of silica-modified titanium dioxide nanoparticles," Journal of Colloid and Interface Science, vol. 288, no. 1, pp. 149-154, 2005.

[36] H. Wei, J. Ren, B. Han, L. Xu, L. Han, and L. Jia, "Stability of polydopamine and poly(DOPA) melanin-like films on the surface of polymer membranes under strongly acidic and alkaline conditions.," Colloids and surfaces. B, Biointerfaces, vol. 110, pp. 22-28, 2013.

[37] M. Falkeborg, P. Paitaid, A. N. Shu, B. Pérez, and Z. Guo, "Dodecenyl succinylated alginate as a novel material for encapsulation and hyperactivation of lipases," Carbohydrate Polymers, vol. 133, Article ID 10094, pp. 194-202, 2015.

[38] A. P. Duarte Moreira, M. Soares Sader, G. D. De Almeida Soares, and M. H. M. R. Leão, "Strontium incorporation on microspheres of alginate/ $\beta$-tricalcium phosphate as delivery matrices," Materials Research, vol. 17, no. 4, pp. 967-973, 2014.

[39] A. Nanci, J. D. Wuest, L. Peru et al., "Chemical modification of titanium surfaces for covalent attachment of biological molecules," Journal of Biomedical Materials Research, vol. 40, no. 2, pp. 324-335, 1998.

[40] C. Zhang, C. Li, S. Huang et al., "Self-activated luminescent and mesoporous strontium hydroxyapatite nanorods for drug delivery," Biomaterials, vol. 31, no. 12, pp. 3374-3383, 2010.

[41] W.-T. Lin, H.-L. Tan, Z.-L. Duan et al., "Inhibited bacterial biofilm formation and improved osteogenic activity on gentamicin-loaded titania nanotubes with various diameters," International Journal of Nanomedicine, vol. 9, no. 1, pp. 12151230, 2014.

[42] K. C. Popat, M. Eltgroth, T. J. LaTempa, C. A. Grimes, and T. A. Desai, "Decreased Staphylococcus epidermis adhesion and increased osteoblast functionality on antibiotic-loaded titania nanotubes," Biomaterials, vol. 28, no. 32, pp. 4880-4888, 2007.

[43] G. Mendonça, D. B. S. Mendonça, F. J. L. Aragão, and L. F. Cooper, "Advancing dental implant surface technology-from micron- to nanotopography," Biomaterials, vol. 29, no. 28, pp. 3822-3835, 2008.

[44] L. Bacakova, E. Filova, M. Parizek, T. Ruml, and V. Svorcik, "Modulation of cell adhesion, proliferation and differentiation on materials designed for body implants," Biotechnology Advances, vol. 29, no. 6, pp. 739-767, 2011.

[45] R. McBeath, D. M. Pirone, C. M. Nelson, K. Bhadriraju, and C. S. Chen, "Cell shape, cytoskeletal tension, and RhoA regulate stem cell lineage commitment," Developmental Cell, vol. 6, no. 4, pp. 483-495, 2004.

[46] S. Panzavolta, P. Torricelli, L. Sturba, B. Bracci, R. Giardino, and A. Bigi, "Setting properties and in vitro bioactivity of strontiumenriched gelatin-calcium phosphate bone cements," Journal of Biomedical Materials Research - Part A, vol. 84, no. 4, pp. 965972, 2008.

[47] E. A. Nunamaker, E. K. Purcell, and D. R. Kipke, "In vivo stability and biocompatibility of implanted calcium alginate disks," Journal of Biomedical Materials Research - Part A, vol. 83, no. 4, pp. 1128-1137, 2007.

[48] L. Fan, M. Cao, S. Gao et al., "Preparation and characterization of sodium alginate modified with collagen peptides," Carbohydrate Polymers, vol. 93, no. 2, pp. 380-385, 2013.
[49] W. Zhang, Y. Shen, H. Pan et al., "Effects of strontium in modified biomaterials," Acta Biomaterialia, vol. 7, no. 2, pp. 800808, 2011.

[50] B. G. Keselowsky, L. Wang, Z. Schwartz, A. J. Garcia, and B. D. Boyan, "Integrin $\alpha 5$ controls osteoblastic proliferation and differentiation responses to titanium substrates presenting different roughness characteristics in a roughness independent manner," Journal of Biomedical Materials Research A, vol. 80, no. 3, pp. 700-710, 2007.

[51] J. Caverzasio, "Strontium ranelate promotes osteoblastic cell replication through at least two different mechanisms," Bone, vol. 42, no. 6, pp. 1131-1136, 2008. 

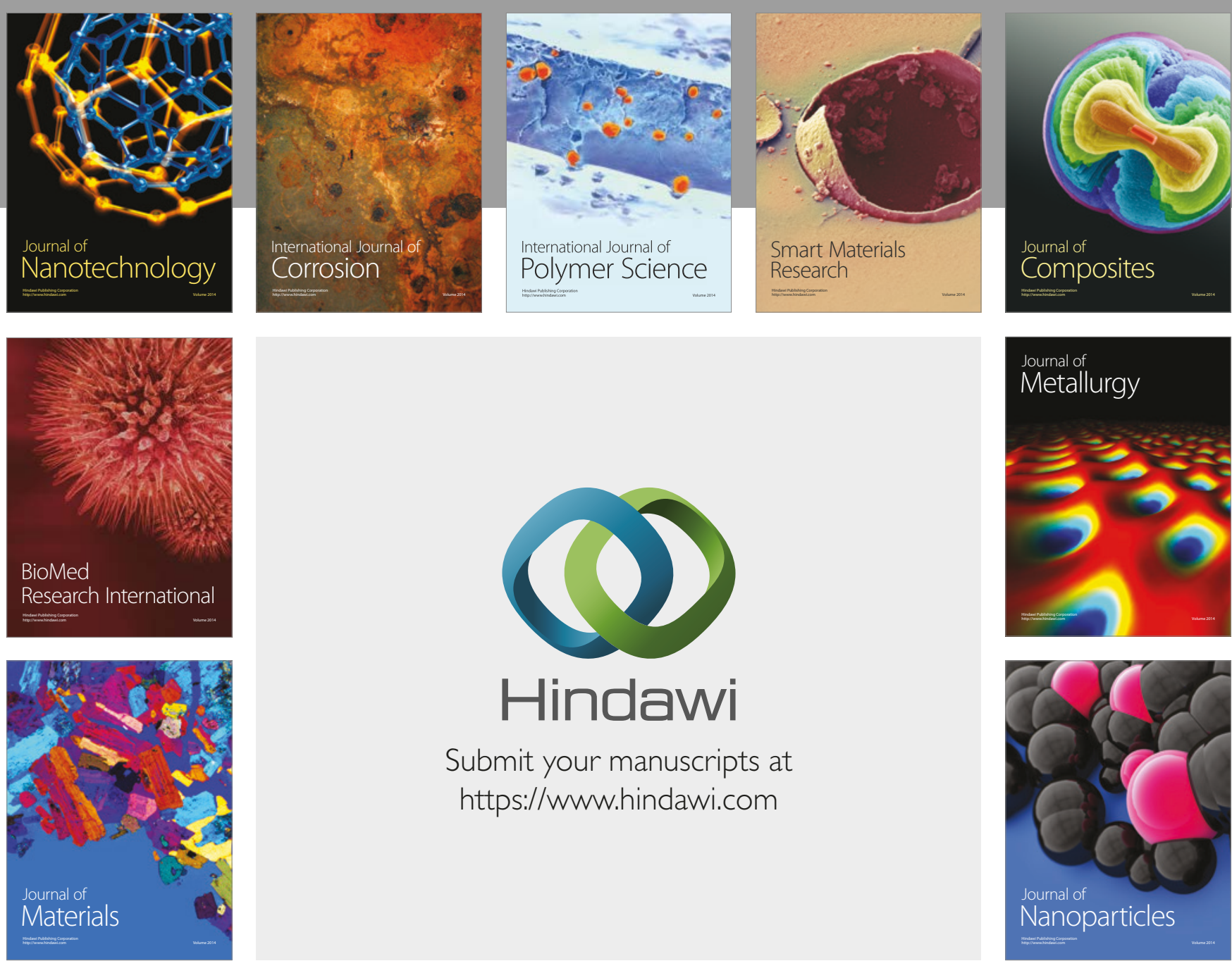

\section{Hindawi}

Submit your manuscripts at

https://www.hindawi.com
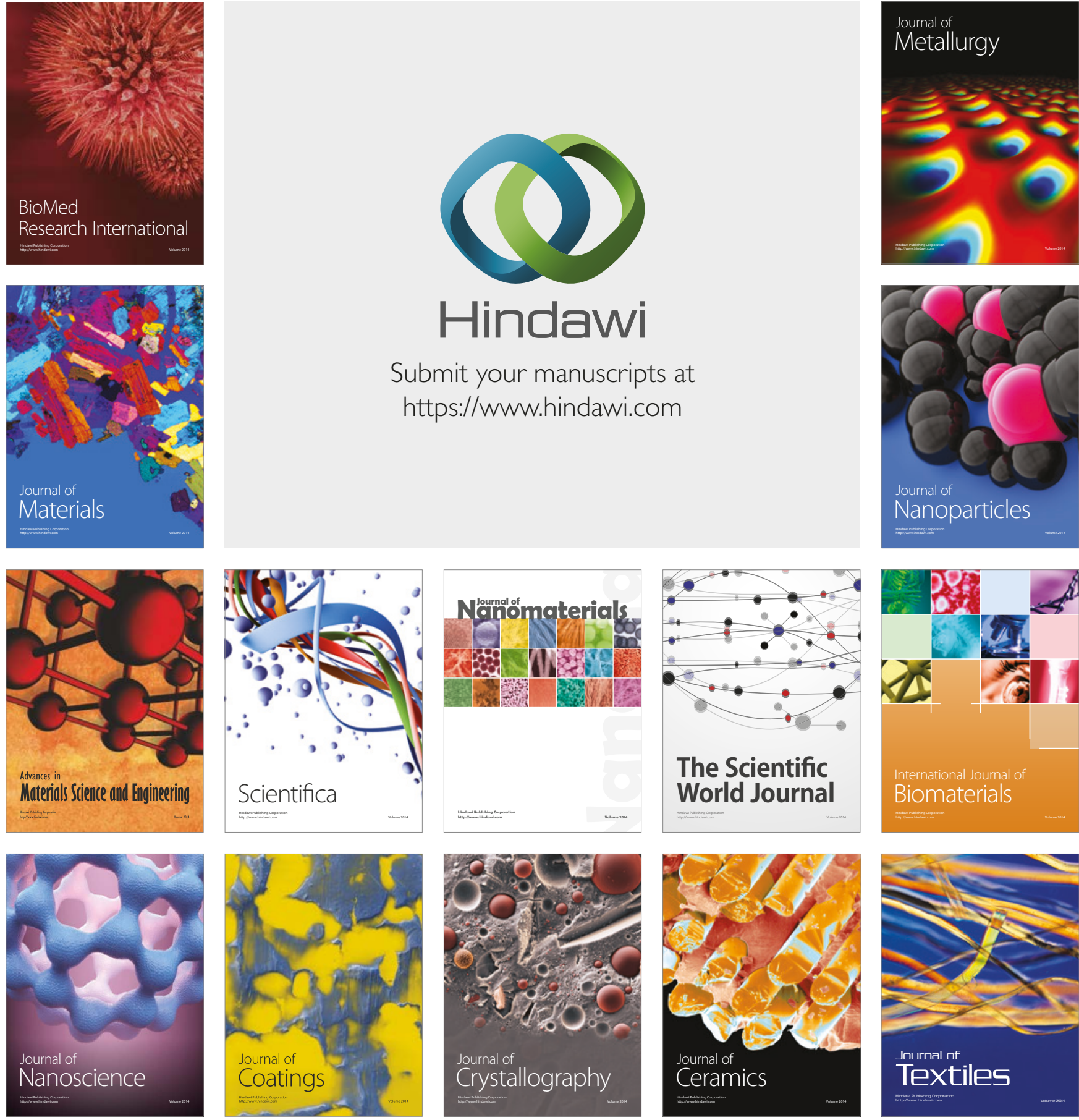

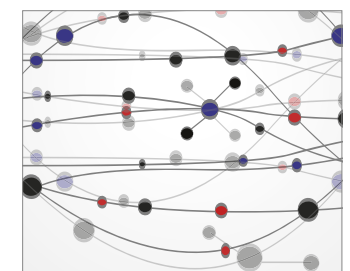

The Scientific World Journal
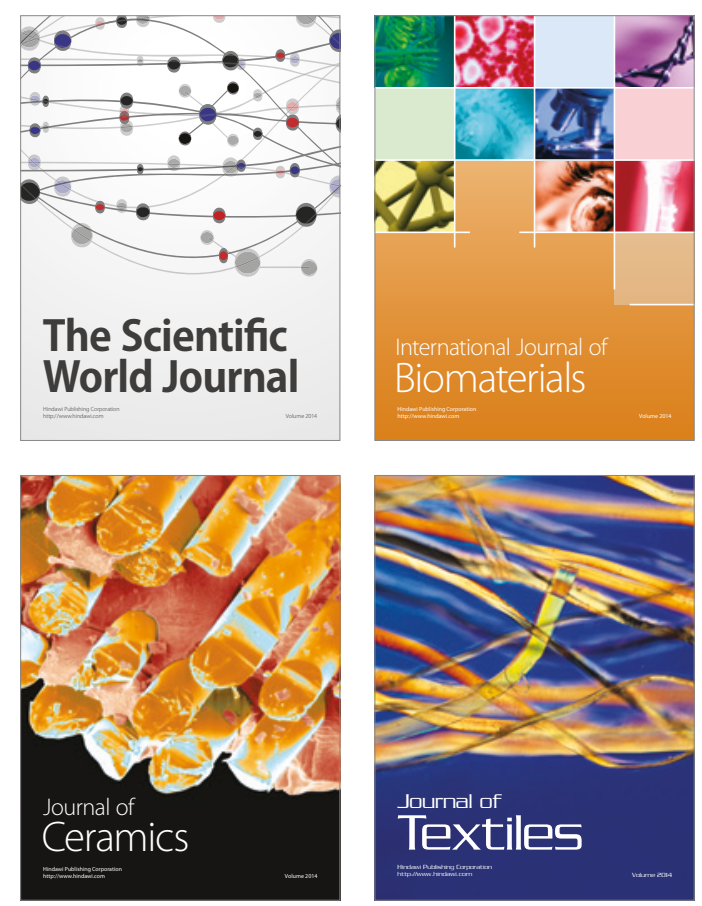